\title{
Comparative efficacy of different laryngoscopes in obese patients: a systematic review and network meta-analysis
}

\author{
Miao Liu \\ Harbin Medical University Cancer Hospital \\ Zhaodi Zhang \\ Harbin Medical University Cancer Hospital \\ Guiyue Wang \\ Harbin Medical University Cancer Hospital \\ Yuhang Li \\ Harbin Medical University Cancer Hospital \\ Kaijiang Yu \\ Harbin Medical University Cancer Hospital \\ changsong wang ( $\nabla$ changsongwangicu@163.com ) \\ Harbin Medical University Cancer Hospital https://orcid.org/0000-0002-0079-5259
}

Research article

Keywords: Obesity; laryngoscopes; meta-analysis

Posted Date: April 5th, 2019

DOI: https://doi.org/10.21203/rs.2.1843/v1

License: (c) (i) This work is licensed under a Creative Commons Attribution 4.0 International License. Read Full License 


\section{Abstract}

Background: Due to changes in the anatomical structure of oral pharynx, increased oxygen consumption and other pathophysiological changes, the airway management of obese patients is complex. Intubation is a critical step, and it is important to choose the optimal laryngoscope. Moreover, the best type of laryngoscopes to use for this population is unclear. The aim of this study is to determine the optimal laryngoscopes for endotracheal intubation in obese patients. Methods: We searched the Cochrane, Medline, EMBASE, EBSCOhost and Web of Science databases for randomized controlled trials comparing video laryngoscopes (VLs) with direct laryngoscopes (DLs) or different brands of VLs in adults with obesity for inclusion in this study. Results: A total of 13 trials with 1264 patients were identified. VLs were associated with an increase in the first-attempt success rate (relative risk (RR) 1.11,95\% confidence interval (Cl) 1.06-1.16), shorter intubation time (MD -13.19, $95 \% \mathrm{Cl}-25.57$ to -0.81 ) and an improved glottic view (RR 1.24, 95\% Cl 1.17-1.30). No difference was observed in the incidence of any complications. In the network meta-analysis, all three types of VLs (Macintosh blade VLs, angulated blade VLs and side-channel blade VLs) were associated with an improved glottic view (RR 1.4, 95\% Cl 1.2-1.7; RR 1.3, 95\% Cl 1.2-1.5; and RR 1.2, 95\% Cl 1.1-1.3, respectively). Conclusions: Compared with DLs, VLs generally increased the success rate on the first-attempt, reduced the intubation time and provided a superior glottic view without increasing complications. All three types of video devices improved visualization of the glottis. Trial registration: This study was registered with the International Prospective Register of Systematic Reviews (PROSPERO 2017: CRD42017079927. http://www.crd.york.ac.uk/PROSPERO).

\section{Background}

Obesity has become a worldwide health concern [1]. An elevated Mallampati score, enlargement of the tongue, a limited mouth opening, reduced cervical mobility and a short thyromental distance are associated with difficult intubation in patients with obesity [2]. In addition to these changes in oral anatomy, patients with obesity have more frequent and rapid oxygen desaturation and increased oxygen consumption and are sensitive to the respiratory depressant effects of anesthetic and analgesic drugs [3,4,5]. Obesity-related anatomic airway changes and alterations in respiratory physiology may increase the difficulty of intubation. Therefore, intubation is more likely to require multiple attempts, be more time consuming, and result in more complications than the intubation of lean patients. Laryngoscopes play a critical role during endotracheal intubation [6]. The use of direct laryngoscopes (DLs) with a Macintosh blade is the most frequent approach and is considered the gold-standard technique due to its effectiveness for endotracheal intubation [3]. Video laryngoscopes (VLs), which have a camera embedded in the distal end of the blade, are advanced devices that provide a direct and illuminated view of the glottis without requiring alignment of the mouth, pharynx and trachea. A wide range of different VLs is available. Some VLs, such as the video-MAC, C-MAC and X-lite VLs, are equipped with blades that resemble the Macintosh blade and enable the device to be used both directly and indirectly.7 Other VLs, such as the GlideScope and McGrath series 5, have angulated blades that differ from the Macintosh blade [7,8]. Other common VLs, such as the Pentax AWS and Airtraq VLs, have side-channel blades that can guide the tracheal tube into the glottis [9].

Recent randomized controlled trials (RCTs) and meta-analyses have drawn opposing conclusions regarding the use of VLs compared to conventional DLs in patients without obesity. Many previous studies have concluded that VLs reduce intubation failure and improve the glottic view $[10,11]$. In contrast, some recent studies have reported that VLs do not improve the first-pass orotracheal intubation rates but instead are associated with increased risks of complications [12,13]. Additionally, several RCTs have emphasized the option of laryngoscope use among patients with obesity. Rania et al observed that Pentax AWS VLs performed better than Macintosh DLs in terms of intubation success [14]. Yumul et al compared three different brands of VLs with the Macintosh DL; although these authors observed that the video-MAC, GlideScope and McGrath VL devices improved visualization of the larynx for tracheal intubation of patients with obesity, McGrath showed a disadvantage in the success rate on the first attempt compared with the Macintosh DLs [3].

Therefore, in view of the controversy described above, whether the use of VLs has advantages in patients with obesity who require endotracheal intubation and which laryngoscope is optimal for patients with obesity are unclear. To the best of our knowledge, no network meta-analysis has explored these issues. Consequently, the aim of our study was to perform a pairwise meta-analysis to compare the effects of VLs and DLs for the intubation of patients with obesity and a network meta-analysis to evaluate the efficacy of different types of laryngoscopes for endotracheal intubation in patients with obesity.

\section{Methods}

\section{Search strategy and selection criteria:}

We followed the Preferred Reporting Items for Systematic Reviews and Meta-Analyses (PRISMA) guidelines to perform our systematic review (Appendix 1) [15]. We searched the Cochrane Central Register of Controlled Trials (CENTRAL) in the Cochrane Library and the Medline, EMBASE, CINAHL and Web of Science databases from database establishment to November 2017. We used the following keywords both individually and in combination: "obesity", "obese", "laryngoscope", "direct laryngoscope", "video laryngoscope", "endotracheal intubation" 
(Appendix 2 for search strategy). In addition, we placed no restrictions on language or year of publication. This study was registered with the International Prospective Register of Systematic Reviews (PROSPERO 2017: CRD42017079927. http://www.crd.york.ac.uk/PROSPERO).

\section{Selection criteria and outcome measures:}

We excluded reviews, observational studies, retrospective studies, animal studies, case reports, irrelevant studies, duplicate studies, manikin studies and trials in patients aged $<18$ years and those with normal body weights. Finally, we included RCTs that compared VLs with DLs or different brands of VLs for endotracheal intubation in obese adult patients (aged $\geq 18$ years). Trials that enrolled patients with obesity considered a body mass index $(\mathrm{BMI}) \geq 30 \mathrm{~kg} / \mathrm{m} 2$ indicative of obesity and were not limited by the type of operation being performed.

The primary outcome was the rate of successful intubation on the first attempt, which was defined as the number of successful endotracheal intubations on the first attempt using a certain type of laryngoscope. The secondary outcomes were the intubation time, the glottic view (Cormack-Lehane grades 1 and 2 or modified Cormack-Lehane classification 1 or 2a, which are considered indications of an easy glottic view) and the incidence of any complications (including a sore throat, tooth and soft tissue injury, the presence of any blood staining on the blade, and glottic swelling). These four outcomes were applied in both the pairwise and network meta-analyses.

In the pairwise meta-analysis, we defined the two groups (the VL and $D L$ groups) according to whether the laryngoscope was or was not equipped with a camera, respectively. In the network meta-analysis, four groups were classified according to the blade forms of the devices and the presence or absence of a camera, as follows: Macintosh blade VLs, angulated blade VLs, side-channel blade VLs and conventional Macintosh DLs.

\section{Data collection and analysis:}

Two authors (ZDZ and GYW) created the search strategy and searched the databases. Three authors (YHL, GYW and ML) independently screened studies based on the title and abstract obtained from the database. Two different groups of authors (ZDZ and GYW for group one; $\mathrm{ML}$ and YHL for group two) read the selected full texts, assessed all trials for eligibility and extracted relevant information using a predefined data extraction form. Any disagreements were settled by KJY.

\section{Statistical analysis:}

The risk of bias of the included trials was assessed by two authors independently using the Cochrane risk of bias tool [16]. The statistical analysis was performed within a Bayesian framework using the GeMTC package in R (version 3.4.1) [17]. The data synthesis was assumed to be feasible if the clinical and methodological heterogeneity were negligible. We used relative risk (RR) values and $95 \%$ confidence intervals (Cls) as approximations to measure the rate of intubation on the first attempt, the glottic view and the incidence of any complications in the included patients with obesity. Mean differences (MDs) and 95\% Cls were used to express the pooled differences in intubation time. Statistical heterogeneity was assessed with the $\mathrm{I}^{2}$ statistic using the Higgins-Thompson method as follows: low heterogeneity, $25 \%$; moderate heterogeneity, 50\%; and high heterogeneity, 75\% [18]. Additionally, clinical heterogeneity was assessed based on the clinical characteristics presented in a clear study table. In the pairwise meta-analysis, a fixed-effects model was used if the heterogeneity was low or moderate $\left(1^{2}<50 \%\right)$. Otherwise, we chose a random-effects model. In addition, a funnel plot (a plot of the treatment effect against the trial precision) and Egger's test were used to evaluate the presence of publication bias. We performed a sensitivity analysis by assessing the effects of removing individual studies on the pooled RR [19]. In the network meta-analyses, model selection was based on the guidelines of Dias et al [20]. The fixed-effects model or random-effects model was chosen for the final analysis according to the deviance information criterion. Furthermore, we used the node-splitting method to assess inconsistencies between direct and indirect sources of evidence.19 Finally, we ranked the different types of laryngoscopes based on their likelihood of leading to an association using the best results for each outcome.

\section{Quality of evidence assessment}

We used the Grading of Recommendations Assessment, Development and Evaluation (GRADE) approach [21] to assess the quality of evidence of each outcome. The quality of evidence was based on the presence of the following: limitations in study design, inconsistencies, indirectness, imprecision of the results, and publication bias. The quality of evidence for the main outcomes was graded very low, low, moderate, or high.

\section{Results}

\section{Study selection:}

Of the 666 studies and abstracts identified in the initial search, 477 were unrelated studies, 143 were study duplicates, 6 were non-RCTs and 2 were manikin studies, which were excluded after screening the titles and abstracts. In total, 38 articles were selected for the full-text review. Finally, 11 RCTs and 2 abstracts were included in our study (Figure 1 depicts the study selection process). 


\section{Summary of studies:}

The 13 studies included a total of 1264 patients with obesity [2,3,14,23-32]. The major characteristics of the included trials are summarized in Table 1. The BMls of the patients were at least $30 \mathrm{~kg} / \mathrm{m} 2$. A total of $92 \%$ of the endotracheal intubations were performed in the operating theatre under general anesthesia.

Study quality:

No double-blinded trials were included in our study. A total of 13 RCTs were identified as having a low to moderate risk of bias according to the Cochrane Collaboration tool. We identified 1 trial with a high risk of bias in sequence generation and 2 trials with a high risk of bias in blinding of the outcome assessors. Postaci et al [31] and Gaszyński et al's [32] studies had an unclear risk of bias. The full risks of bias are summarized in Appendix 3 Figure S1-S2.

\section{Pairwise meta-analysis:}

A total of 12 trials with 1188 patients with obesity were included in the pairwise meta-analysis, which compared the efficacies of VLs versus DLs for endotracheal intubation. The results revealed differences in the rate of successful intubation on the first attempt $[2,3,14,23-25,27,28,30]$ ( $94 \%$ vs $86 \%$, RR $1.11,95 \% \mathrm{Cl} 1.06$ to $1.16, \mathrm{P}<0.0001$ ), the intubation time $[2,3,14,23-25,27-32]$ (38s vs $48 \mathrm{~s}, \mathrm{MD}-13.19,95 \% \mathrm{Cl}-2.57$ to -0.81 ) and the glottic view $[2,3,14,24,25,27-29]$ ( $97 \%$ vs $79 \%, \mathrm{RR} 1.24,95 \% \mathrm{Cl} 1.17$ to $1.30, \mathrm{P}<0.0001)$. The numbers needed to treat to achieve an additional successful intubation and superior glottic view were 11 and 6 , respectively. We noted heterogeneity in the rate of successful intubation on the first attempt ( $12=30.8 \%$, moderate), the intubation time $(12=98.0 \%$, high) and the glottic view $(12=40.0 \%$, moderate). No significant difference was observed in the incidence of any complications $[2,3,14,23-25,27,28,30](28.6 \%$ vs $20.3 \%, \mathrm{RR} 1.24,95 \% \mathrm{Cl} 0.93$ to $1.67, \mathrm{P}=0.1495,12=2.3 \%$, low) (Figure 2). No evidence of publication bias was observed in the funnel plot (Appendix 3 Figure S3-S6). The sensitivity analysis showed no substantive difference except for intubation time in Dhonneu's [29] trial. Dhonneu's study was a large sample study. Therefore, it had a larger weight of results than the other trials. As this study was well designed and met our inclusion criteria, it could not be excluded (Appendix 3 Figure S7).

\section{Subgroup analysis of the primary outcome:}

Subgroup analysis was performed, and the results showed that Macintosh blade VLs (RR 1.19; 95\% Cl 1.08 to 1.13 ) and angulated blade VLs (RR 1.12; 95\% Cl 1.01 to 1.25) increased the successful intubation rate compared with conventional Macintosh DLs. However, side-channel VLs versus conventional Macintosh DLs showed no statistical significance (RR 1.07; 95\% Cl 1.00 to 1.13). (Figure 3)

\section{Network meta-analysis:}

A network meta-analysis of 12 trials including a total of 1180 patients with obesity was conducted to compare the efficacy of the following four different types of laryngoscopes according to the shapes of the blades: the Macintosh blade VL, the angulated blade VL, the side-channel blade VL and the conventional Macintosh DL. Figure 4 shows the network of eligible comparisons. The pooled effect sizes suggest that compared with the conventional Macintosh DLs, the Macintosh blade VLs (RR 1.4, 95\% $\mathrm{Cl} 1.2$ to 1.7 ), the angulated blade VLs (RR $1.4,95 \% \mathrm{Cl}$ 1.2 to 1.7 ) and the side-channel blade VLs (RR $1.2,95 \% \mathrm{Cl} 1.1$ to 1.3 ) offered an improved glottic view $[2,3,14,24-29]$. Comparisons of the complications $[2,3,14,23-25,28,32]$ induced by intubation showed differences between the side-channel blade VLs and conventional Macintosh DLs compared to angulated blade VLs (RR $0.51,95 \% \mathrm{Cl} 0.29$ to 0.87 ; and RR $0.71,95 \% \mathrm{Cl} 0.52$ to 0.98 , respectively). The combined results showed no significant differences in the rate of successful intubation on the first attempt $[2,3,14,23-28,30]$ and the intubation time $[2,14,23-30]$.

For probability ranking, we found that the Macintosh blade VLs had the greatest potential to improve the rate of successful intubation on the first attempt and the glottic view. The probabilities of Macintosh blade VLs holding the top ranking for these two outcomes were $77 \%$ and $80 \%$. The conventional Macintosh DLs were estimated to be the fastest laryngoscopy device (probability was $72 \%$ ). The side-channel blade VLs were likely the worst approach with respect to complications (probability was $81 \%$ ). The probability rankings for the four outcomes are summarized in Appendix 3 Figure S8.

The $p$ values were greater than 0.05 for the inconsistency tests of each outcome. No statistical inconsistencies were identified between the direct and indirect comparisons using the node-splitting method (Appendix 3 Figure S9-S12).

\section{Quality of evidence assessment:}

Because the operator could not be blinded to the device, the evaluation may be at a high risk of bias. The quality of evidence was ranked as "moderate" for the effect of the VLs and DLs on the rate of successful intubation on the first attempt and the glottic view. The quality of evidence for complications was "low" because the sample size did not reach the optimal information size. For intubation time, the quality of evidence was graded "very low" due to high heterogeneity (Appendix 4).

\section{Discussion}


To the best of our knowledge, this study is the first network meta-analysis of randomized control trials to evaluate and compare VLs and DLs among patients with obesity. In previous studies, Du et al [12] and Lascarrou et al [13] reported that VLs did not improve the first-pass orotracheal intubation rates in critically ill patients requiring intubation but instead were associated with higher rates of severe life-threatening complications. These differences were mainly due to the included populations. Previous studies did not consider obesity as a critical factor, whereas our study enrolled patients with obesity who may have had special anatomical and physiological structures that could increase the difficulty of intubation. The potential benefits of an improved view of the glottis using VLs are that adverse events associated with a blind intubation can be avoided and that novitiates may gain a better understanding of airway anatomy [33]. Recently, Hoshijima et al [34] performed a conventional meta-analysis comparing VLs with Macintosh laryngoscopes for tracheal intubation in adults with obesity. We found that one trial [35] included in this work did not meet the inclusion criteria. This trial compared the use of McGrath Series 5 VLs with Macintosh DL in obstetric patients with BMls of $(27.98 \pm 3.22) \mathrm{kg} / \mathrm{m} 2$ and $(29.45 \pm 5.60) \mathrm{kg} / \mathrm{m} 2$ in each group.

High heterogeneity was observed in the outcome of intubation time. The source of this heterogeneity is likely that the authors of each RCT developed their own criteria for defining the end of a failed intubation. Therefore, the success of an intubation may be defined as an overtime intubation in one study but as a failed intubation in another study. High heterogeneity may introduce doubt concerning the reliability of the results.

Regarding the glottic view, all VL types seemed to be superior to the Macintosh DLs. Furthermore, the Macintosh blade VLs performed the best. Generally, experienced doctors are able to master the use of the conventional Macintosh laryngoscope [36]. The VL with the Macintosh blade has a classical blade shape and radian but can capture the glottic image through a camera device at the tip of the blade [37]. Hence, this type of laryngoscope increases the success of endotracheal intubation and visualization of the glottis.

In a comparison of complications, the three types of VLs and the Macintosh DLs showed no significant differences. However, the side-channel blade VLs had the highest likelihood of complications, possibly due to the bulky interlock component of this type of VL [9]. In the relatively narrow oral environment of patients with obesity, intense pressure is often required to maneuver the distal tip of the blade beyond the tongue when using the side-channel blade VLs, and an abrupt loss of resistance occurs as the tip of the blade finally passes into the oropharyngeal space. This issue may explain why these types of laryngoscope have the highest incidence of damage to oral tissues. The angulated blade VLs had the lowest likelihood of complications because of the design of their blades, which bend at $45^{\circ}$ in the McGrath Series 5 and $60^{\circ}$ in the GlideScope; these angles are consistent with the physiological curvature of the human oropharynx [38]. When the blade is positioned below the epiglottis, the camera is positioned just in front of the glottis. Therefore, the probability of complications is low.

The interaction of 4 variables may determine the success of endotracheal intubation: the population characteristics, the anesthetist's skills, the duration of the surgical procedure and the available devices. In addition to different laryngoscopes, operator skill, standardized patient positioning, and the use of bougies or stylets should be considered further [39].

Some limitations of this meta-analysis warrant consideration. First, head-to-head trials assessing the efficacy of different laryngoscopes in obese patients are limited. The network meta-analysis may rely more heavily on indirect comparisons. Thus, the results of the network metaanalysis are more prone to producing false negative or false positive results. The side-channel VLs subgroup included 4 studies and comprised $46.6 \%$ of the sample size for this outcome. The large weight of this subgroup may have led to the negative combined results in the network meta-analysis. Because of the difference in statistical analysis between direct and indirect comparisons, when the number of studies is small, the results may be inconsistent [40]. Future multicenter comparisons involving larger sample sizes and direct parallel comparisons between different laryngoscopes are needed to confirm our results. Second, we defined obesity according to the internationally recognized cut-off BMI value for adults (BMl $\geq 30 \mathrm{~kg} / \mathrm{m} 2)$. However, patients with morbid obesity (BMl $\geq 35 \mathrm{~kg} / \mathrm{m} 2)$ were included in some of the enrolled studies, a factor that needs further consideration [41]. In addition, for patients with obesity who require endotracheal intubation, the prevention of complications associated with laryngoscope use is a key step [42]. However, in the RCTs included in our study, the definition of complications, which included a sore throat, tooth and soft tissue injury, the presence of any blood staining the blade and glottic swelling, was not unified. The included trials referred to only one or more complications with no consideration of the premorbid status or analgesic regimen. No comprehensive and standard statistics were recorded. Therefore, we counted only the number of patients who experienced the complications listed above. In addition, regarding cardiovascular complications, only two RCTs recorded an SpO2<92\% during intubation, and only one RCT recorded an SpO2<77\%. Thus, we did not include cardiovascular complications in our final list of complications. These results must be interpreted with caution. Third, because the operator could not be blinded to the device used in the enrolled RCTs, the quality of the evaluation may be at a higher risk.

In conclusion, compared with DLs, VLs generally increased the rate of endotracheal intubation on the first attempt, reduced intubation time and provided a superior glottic view in patients with obesity, with no increase in the risk of complications. Although there was no significant advantage in success rate or intubation time, our network results demonstrated that the use of video devices (Macintosh blade VLs, angulated blade VLs and side-channel blade VLs) could improve visualization of glottis compared with the use of DLs. Compared with side-channel blade VLs and conventional Macintosh VLs, the angulated blade VLs reduced the complications associated with intubation.

Page 5/14 


\section{List Of Abbreviations}

VLs: video laryngoscopes

DLs: direct laryngoscopes

RR: relative risk

Cl: confidence interval

BMI: body mass index

MD: mean difference

RCT: randomized control trial

\section{Declarations}

\section{Ethics approval and consent to participate}

Not applicable.

\section{Consent for publication}

Not applicable.

\section{Availability of data and materials}

All data supporting the conclusions presented in this article are included in this published article.

\section{Competing interests:}

The authors declare that they have no competing interests.

\section{Funding:}

This study was funded by the National Natural Science Foundation of China (81571871 and 81770276), the Yuweihan Fund for Distinguished Young Scholars and Nn10 program of Harbin Medical University Cancer Hospital. The authors have no conflicts of interest.

\section{Authors' contributions:}

ZDZ and GYW searched five databases. YHL, GYW and ML screened the articles. ZDZ, GYW, ML and YHL were divided into two groups and viewed the full-text and extracted the data from each study, independently. ML and CSW conceived the study and contributed data. Any disagreements were decided by KJY.

\section{Acknowledgment:}

We would like to thank the all study authors who provided additional data to complete these reviews.

\section{Authors' information:}

1.Department of Critical Care Medicine, Harbin Medical University Cancer Hospital. Harbin, China. 2.Department of Anesthesiology, Harbin Medical University Cancer Hospital. Harbin, China.

\section{References}

1.Aceto P, Perilli V, Modesti C, Ciocchetti P, Vitale F, Sollazzi L. Airway management in patients with obesity. Surg Obes Relat Dis. 2013; 9: 80915

2. S. K. Ndoko, R. Amathieu, L. Tual, Polliand C, Kamoun W, El Housseini L, Champault G, Dhonneur G. Tracheal intubation of morbidly patients with obesity: a randomized trial comparing performance of Macintosh and AirtraqTM laryngoscopes. British Journal of Anaesthesia. 2008; 100: $263-8$. 
3. Yumul R, Elvir-Lazo OL, White PF, Sloninsky A, Kaplan M, Kariger R, Naruse R, Parker N, Pham C, Zhang X, Wender RH. Comparison of three video laryngoscopy devices to direct laryngoscopy for intubating obesepatients: a randomized controlled trial. J Clin Anesth. 2016; 31:71-7.

4. Benumof JL. Obesity, sleep apnea, the airway and anesthesia. Curr Opin Anaesthesiol. 2004; 17: 21-30.

5. Adams JP, Murphy PG. Obesity in anaesthesia and intensive care. Br J Anaesth. 2000; 85: 91-108.

6. Juvin P, Lavaut E, Dupont H, Lefevre P, Demetriou M, Dumoulin JL, Desmonts JM. Difficult tracheal intubation is more common in obese than in lean patients. Anesth Analg. 2003; 97: 595-600.

7. Pieters BM, Wilbers NE, Huijzer M, Winkens B, van Zundert AA. Comparison of seven videolaryngscopes with the Macintosh laryngoscope in manikins by experienced and novice personnel. Anaesthesia. 2016; 71: 556-64.

8. Niforopoulou P, Pantazopoulos I, Demestiha T, Koudouna E, Xanthos T. Video-laryngoscopes in the adult airway management: a topical review of the literature. Acta Anaesthesiol Scand. 2010; 54: 1050-61.

9. Chalkeidis O, Kotsovolis G, Kalakonas A, et al. A comparison between the Airtraq and Macintosh laryngoscopes for routine airway management by experienced anesthesiologists: a randomized clinical trial. Acta Anaesthesiol Taiwan. 2010; 48: 15-20.

10. Griesdale DE, Liu D, McKinney J, Choi PT. Glidescope® video-laryngoscopy versus direct laryngoscopy for endotracheal intubation: a systematic review and meta-analysis. Can J Anaesth. 2012; 59: 41-52.

11. Suppan L, Tramèr MR, Niquille M, Grosgurin 0 , Marti C. Alternative intubation techniques vs Macintosh laryngoscopy in patients with cervical spine immobilization: systematic review and meta-analysis of randomized controlled trials. Br J Anaesth. 2016; 116: 27-36.

12. Huang HB, Peng JM, Xu B, Liu GY, Du B. Video laryngoscopy for Endotracheal Intubation of Critically III Adults: a systemic review and metaanalysis. Chest. 2017; 152: 510-7.

13. Lascarrou JB, Boisrame-Helms J, Bailly A, Le Thuaut A, Kamel T, Mercier E, Ricard JD, Lemiale V, Colin G, Mira JP, Meziani F, Messika J, Dequin PF, Boulain T, Azoulay E, Champigneulle B, Reignier J; Clinical Research in Intensive Care and Sepsis (CRICS) Group. Video Laryngoscopy vs Direct Laryngoscopy on Successful First-Pass Orotracheal Intubation Among ICU Patients: A Randomized Clinical Trial. JAMA. 2017; 317: 483-93.

14. Abdallah R, Galway U, You J, Kurz A, Sessler DI, Doyle DJ. A randomized comparison between the Pentax AWS video laryngoscope and the Macintosh laryngoscope in morbidly patients with obesity. Anesth Analg. 2011; 113: 1082-7.

15. Moher D, Liberati A, Tetzlaff J, Altman DG, PRISMA Group. Preferred reporting items for systematic reviews and meta-analyses: the PRISMA statement. PLoS Med. 2009; 21: e1000097.

16. Higgins JPT, Green S. Cochrane handbook for systematic reviews of interventions, version 5.1.0. Cochrane Collaboration, Oxford, 2012.

17. Dias S, Welton NJ, Caldwell DM, Ades AE. Checking consistency in mixed treatment comparison meta-analysis. Stat Med. $2010 ; 29$ : 932-44.

18. Higgins JP, Thompson SG, Deeks JJ, Altman DG. Measuring inconsistency in meta-analyses. BMJ. 2003; 327: 557-60.

19. Egger M, Davey Smith G, Schneider M, Minder C. Bias in meta-analysis detected by a simple, graphical test. BMJ. 1997; $315: 629-34$.

20. Dias S, Welton NJ, Sutton AJ, Ades AE. A Generalised Linear Modelling Framework for Pairwise and Network Meta-Analysis of Randomised Controlled Trials. London: National Institute for Health and Care Excellence (NICE); 2014.

21. Guyatt GH, Oxman AD, Santesso N, Helfand M, Vist G, Kunz R, Brozek J, Norris S, Meerpohl J, Djulbegovic B, Alonso-Coello P, Post PN, Busse JW, Glasziou P, Christensen R, Schünemann HJ. GRADE guidelines: 12. Preparing summary of findings tables-binary outcomes. J Clin Epidemiol. 2013; 66: 158-172.

22. Tryba M, Cook D, Tryba M. Current guidelines on stress ulcer prophylaxis. Drugs. 1997; 54: 581-96.

23. Ander F, Magnuson A, Berggren L, Ahlstrand R, de Leon A. Time-to-intubation in patients with obesity. A randomized study comparing direct laryngoscopy and videolaryngoscopy in experienced anesthetists. Minerva Anestesiol. 2017; 83: 906-13.

24. Andersen LH, Rovsing L, Olsen KS. GlideScope videolaryngoscope vs. Macintosh direct laryngoscope for intubation of morbidly patients with obesity: a randomized trial. Acta Anaesthesiol Scand. 2011; 55: 1090-7. 
25. Castillo-Monzón CG, Marroquín-Valz HA, Fernández-Villacañas-Marín M, Moreno-Cascales M, García-Rojo B, Candia-Arana CA. Comparison of the macintosh and airtraq laryngoscopes in morbidly patients with obesity: a randomized and prospective study. J Clin Anesth. 2017; 36 : 136-41.

26. Putz L, Dangelser G, Constant B, Jamart J, Collard E, Maes M, Mayné A. Prospective trial comparing Airtraq and Glidescope techniques for intubation of patients with obesity. Ann Fr Anesth Reanim. 2012; 31: 421-6.

27. Ranieri D Jr, Filho SM, Batista S, do Nascimento P Jr. Comparison of Macintosh and Airtraq ${ }^{\text {TM }}$ laryngoscopes in patients with obesity placed in the ramped position. Anaesthesia. 2012; 67: 980-5.

28. Yousef GT, Abdalgalil DA, Ibrahim TH. Orotracheal intubation of morbidly patients with obesity, comparison of GlideScope(®) video laryngoscope and the LMA CTrach ${ }^{\mathrm{TM}}$ with direct laryngoscopy. Anesth Essays Res. 2012; 6: 174-9.

29. Dhonneur G, Abdi W, Ndoko SK, Amathieu R, Risk N, El Housseini L, Polliand C, Champault G, Combes X, Tual L. Video-assisted versus conventional tracheal intubation in morbidly patients with obesity. Obes Surg. 2009; 19: 1096-101.

30. Marrel J, Blanc C, Frascarolo P, Magnusson L. Videolaryngoscopy improves intubation condition in morbidly patients with obesity. Eur J Anaesthesiol. 2007; 24: 1045-9.

31. Postaci A, Çakirca M, Saçan Ö, Aytaç I, Sakizci Uyar B, Başkan S, Baydar M., Özkoçak Turan I. Comparison of the mcgrath series 5 videolaryngoscope to the standard macintosh laryngoscope for the intubation of the patients with obesity. Anestezi Dergisi. $2015 ; 23$ : 126-30.

32. Gaszyński T, Gaszyński W. A comparison of the optical AirTraq and the standard Macintosh laryngoscope for endotracheal intubation in patients with obesity. Anestezjologia intensywna terapia. 2009; 41: 145-8.

33. Maldini B, Hodžović I, Goranović T, Mesarić J. Challenges in the use of video laryngoscopes. Acta Clin Croa. 2016; 55: 41-50.

34. Hoshijima H, Denawa Y, Tominaga A, Nakamura C, Shiga T, Nagasaka H. Videolaryngoscope versus Macintosh laryngoscope for tracheal intubation in adults with obesity: A systematic review and meta-analysis. J Clin Anesth. 2018; 44: 69-75.

35. Arici S, Karaman S, Doğru S, Karaman T, Tapar H, Özsoy AZ, Kaya Z, Süren' M. The McGrath Series 5 video laryngoscope versus the Macintosh laryngoscope: a randomized trial in obstetric patients. Turk J Med Sci. 2014; 44: $387-92$.

36. Cavus E, Byhahn C, Dörges V. Classification of videolaryngoscopes is crucial. Br J Anaesth. 2017; 118: 806-7.

37. Hsiao WT, Lin YH, Wu HS, Chen CL. Does a new videolaryngoscope (glidescope) provide better glottic exposure? Acta Anaesthesiol Taiwan. 2005; 43: 147-51.

38. Griesdale DE, Liu D, McKinney J, Choi PT. Glidescope® video-laryngoscopy versus direct laryngoscopy for endotracheal intubation: a systematic review and meta-analysis. Can J Anaesth. 2012; 59: 41-52.

39. Hirabayashi Y, Hoshijima H, Kuratani N. Efficacy of Pentax-AWS in difficult airways: a meta-analysis of randomized controlled trials. Masui. 2013; 62: 737-44.

40. Glenny AM, Altman DG, Song F, Sakarovitch C, Deeks JJ, D'Amico R, Bradburn M, Eastwood AJ; International Stroke Trial Collaborative Group.. Indirect comparisons of competing interventions. Health Technol Assess. 2005; 9: 1-134, iii-iv.

41. Brauer P, Connor Gorber S, Shaw E, Singh H, Bell N, Shane AR, Jaramillo A, Tonelli M, Canadian Task Force on Preventive Health Care. Recommendations for prevention of weight gain and use of behavioural and pharmacologic interventions to manage overweight and obesity in adults in primary care. CMAJ. 2015; 187: 184-95.

42. Aqil M, Khan MU, Mansoor S, Khokhar RS, Narejo AS. Incidence and severity of postoperative sore throat: a randomized comparison of Glidescope with Macintosh laryngoscope. BMC Anesthesiol. 2017; 17: 127.

\section{Tables}

Table 1: Characteristics of included trials 


\begin{tabular}{|c|c|c|c|c|c|c|c|}
\hline First author & Country & $\begin{array}{l}\text { Number of } \\
\text { patients(n) }\end{array}$ & Intervention(n) & $\begin{array}{l}\text { BMI of each } \\
\text { group }(\mathrm{kg} / \mathrm{m} 2)\end{array}$ & $\begin{array}{l}\text { Mallampatii } \\
\text { Score( }(\nabla / \nabla / \\
\nabla / \nabla)(\mathrm{n})\end{array}$ & Outcomes & Operators \\
\hline \multirow[t]{2}{*}{ Abdallah(2011)12 } & \multirow[t]{2}{*}{ USA } & \multirow[t]{2}{*}{99} & Pentax AWS(50) & & $21 / 18 / 7 / 4$ & \multirow{2}{*}{$\begin{array}{l}(1)(2)(3) \\
(4)\end{array}$} & \multirow{2}{*}{$\begin{array}{l}\text { Attending } \\
\text { anesthesiologists, } \\
\text { each of whom had } \\
\text { previously used } \\
\text { the Pentax AWS } 5 \\
\text { to } 10 \text { times before } \\
\text { the study began }\end{array}$} \\
\hline & & & $\begin{array}{l}\text { Macintosh size } 4 \\
\text { blade(49) }\end{array}$ & $42.5 \pm 5.9$ & $14 / 21 / 13 / 0$ & & \\
\hline \multirow[t]{2}{*}{ Ander(2017)20 } & \multirow[t]{2}{*}{ Sweden } & \multirow[t]{2}{*}{80} & $\begin{array}{l}\text { the Storz C- } \\
\text { MAC(40) }\end{array}$ & & & \multirow[t]{2}{*}{$(1)(2)(4)$} & \multirow{2}{*}{$\begin{array}{l}\text { Anesthetists } \\
\text { experienced with } \\
\text { both devices }\end{array}$} \\
\hline & & & $\begin{array}{l}\text { Macintosh size } 3 \\
\text { blade(40) }\end{array}$ & $39.9 \pm 4.0$ & $8 / 28 / 3 / 0$ & & \\
\hline \multirow[t]{2}{*}{ Andersen(2011)21 } & \multirow[t]{2}{*}{ Denmark } & \multirow[t]{2}{*}{100} & $\begin{array}{l}\text { Glidescope GVL } \\
\text { size } 4(50)\end{array}$ & $42 \pm 6$ & $\geq \bigotimes: 11$ & \multirow[t]{2}{*}{$\begin{array}{l}(1)(2)(3) \\
4)\end{array}$} & $\begin{array}{l}\text { one of five } \\
\text { certified }\end{array}$ \\
\hline & & & $\begin{array}{l}\text { Macintosh size } 3 \\
\text { or } 4 \text { blade }(50)\end{array}$ & $\begin{array}{l}-10 \\
0\end{array}$ & - & & $\begin{array}{l}\text { nurse anesthetists } \\
\text { or two } \\
\text { anesthesiologists } \\
\text { all with prior } \\
\text { experience from at } \\
\text { least } 20 \mathrm{GS} \\
\text { intubations and } \\
\text { with wide } \\
\text { experience in } \\
\text { anesthetizing } \\
\text { patients with } \\
\text { obesity }\end{array}$ \\
\hline \multirow{2}{*}{$\begin{array}{l}\text { Castillo-Monzón } \\
(2017) 22\end{array}$} & \multirow[t]{2}{*}{ Spain } & \multirow[t]{2}{*}{46} & Airtraq(23) & $45.97 \pm 3.61$ & $1 / 9 / 13 / 0$ & \multirow{2}{*}{$\left(\begin{array}{l}1)(2)(3) \\
4)\end{array}\right.$} & \multirow[t]{2}{*}{ NA } \\
\hline & & & Macintosh(23) & $46.87 \pm 4.38$ & $2 / 14 / 7 / 0$ & & \\
\hline \multirow[t]{2}{*}{ Dhonneur(2008)26 } & \multirow[t]{2}{*}{ France } & \multirow[t]{2}{*}{212} & Airqraq(106) & $43 \pm 6$ & $41 / 41 / 21 / 3$ & \multirow[t]{2}{*}{$(2)(3)(4)$} & \multirow[t]{2}{*}{ NA } \\
\hline & & & Macintosh(106) & $40 \pm 7$ & $39 / 44 / 23 / 0$ & & \\
\hline \multirow[t]{2}{*}{ Gaszyński(2009)29 } & \multirow[t]{2}{*}{$\mathrm{N} / \mathrm{A}$} & \multirow[t]{2}{*}{68} & Airtraq(34) & $>39$ & $\mathrm{~N} / \mathrm{A}$ & \multirow[t]{2}{*}{$(2)$} & \multirow[t]{2}{*}{ NA } \\
\hline & & & Macintosh(34) & $>39$ & & & \\
\hline \multirow[t]{2}{*}{ Marrel(2007)27 } & \multirow[t]{2}{*}{ Switzerland } & \multirow[t]{2}{*}{80} & X-lite(40) & $42.8 \pm 6.9$ & 14/13/10/3 & $(1)(2)$ & senior \\
\hline & & & Macintosh(40) & $43.5 \pm 5.4$ & $12 / 15 / 9 / 4$ & & $\begin{array}{l}\text { with experience in } \\
\text { the use of the } \\
\text { videolaryngoscope }\end{array}$ \\
\hline Ndoko(2008)2 & France & 106 & Airtraq(53) & $44 \pm 6$ & 15/22/10/6 & $\left(\begin{array}{l}1 \\
4\end{array}\right)(2)(3)$ & $\begin{array}{l}\text { All } \\
\text { anaesthesiologists }\end{array}$ \\
\hline & & & Macintosh(53) & $43 \pm 5$ & $17 / 20 / 11 / 5$ & & $\begin{array}{l}\text { performing } \\
\text { tracheal } \\
\text { intubations were } \\
\text { skilled in the use } \\
\text { of the AirtraqTM } \\
\text { and Macintosh } \\
\text { laryngoscopes } \\
\text { and frequently } \\
\text { anaesthetize for } \\
\text { obesity surgery. }\end{array}$ \\
\hline Postaci(2015)28 & N/A & 84 & $\begin{array}{l}\text { Video- } \\
\text { laryngoscope(42) }\end{array}$ & $\geq 30$ & N/A & $(2)$ & NA \\
\hline & & & Macintosh(42) & $\geq 30$ & & & \\
\hline Putz(2012)25 & Belgium & 76 & $\begin{array}{l}\text { Glidescope GVL } \\
\text { blade } 3(38)\end{array}$ & & $7 / 7 / 18 / 6$ & $(1)(3)$ & NA \\
\hline & & & Airtraq(38) & & $/ 2$ & & \\
\hline Ranieri(2012)26 & $\begin{array}{l}\text { the New } \\
\text { Zealand }\end{array}$ & 132 & Airtraq size 3(68) & $43.5 \pm 6.3$ & $9 / 33 / 22 / 4$ & $(1)(2)(3)$ & $\begin{array}{l}\text { The four } \\
\text { participating }\end{array}$ \\
\hline & & & $\begin{array}{l}\text { Macintosh } 3,4 \text { or } \\
5 \text { blade(64) }\end{array}$ & $42.7 \pm 4.4$ & $6 / 32 / 21 / 5$ & & $\begin{array}{l}\text { anaesthetists had } \\
\text { more than five }\end{array}$ \\
\hline
\end{tabular}


years of clinical experience with conventional

laryngoscopy and had used the

Airtraq

laryngoscope on

manikins and for a

minimum of 50

patients.

\begin{tabular}{|c|c|c|c|c|c|c|}
\hline \multirow[t]{2}{*}{ Yousef(2012)25 } & \multirow[t]{2}{*}{ Egypt } & \multirow[t]{2}{*}{60} & Glidescope(30) & $43.2 \pm 7.4$ & $1 / 4 / 18 / 7$ & \multirow{2}{*}{$\begin{array}{l}(1)(2)(3) \\
(4)\end{array}$} \\
\hline & & & Macintosh(30) & $43.6 \pm 9.5$ & $0 / 3 / 20 / 7$ & \\
\hline
\end{tabular}

All

anesthesiologists

performing

tracheal

intubations were

trained in

manikins in the use of Glidescope

laryngoscopes

and Macintosh

laryngoscopes

\begin{tabular}{|c|c|c|c|c|c|c|c|}
\hline \multirow[t]{4}{*}{ Yumul(2016)3 } & \multirow[t]{4}{*}{ USA } & \multirow[t]{4}{*}{121} & Video-MAC(30) & $43 \pm 8$ & $5 / 17 / 7 / 1$ & \multirow{4}{*}{$(1)(2)(3)$} & \multirow{4}{*}{$\begin{array}{l}\text { All } \\
\text { anesthesiologists } \\
\text { performing the } \\
\text { tracheal } \\
\text { intubations had } \\
\text { been previously } \\
\text { trained using all } \\
\text { three VL devices } \\
\text { (with a minimum } \\
\text { of } 20 \text { intubations } \\
\text { with each device). }\end{array}$} \\
\hline & & & $\begin{array}{l}\text { Glidescope } \\
\text { GVL(30) }\end{array}$ & & $5 / 13 / 12 / 0$ & & \\
\hline & & & McGrath Series & $41 \pm 6$ & $4 / 19 / 7 / 0$ & & \\
\hline & & & $\begin{array}{l}5(30) \\
\text { Macintosh }(31)\end{array}$ & $42 \pm 5$ & $1 / 20 / 10 / 0$ & & \\
\hline
\end{tabular}

N/A: not available; (1) successful intubation rate on the first attempt; (2) intubation time; (3) glottic view; (4) the incidence of any complications.

\section{Figures}


666 records identified through database searching

170 The Cochrane Library

201 Embase

98 MEDLINE

111 EBSCOhost

86 Web of Science

116 duplicates excluded

530 excluded based on title and abstract review

550 records screened

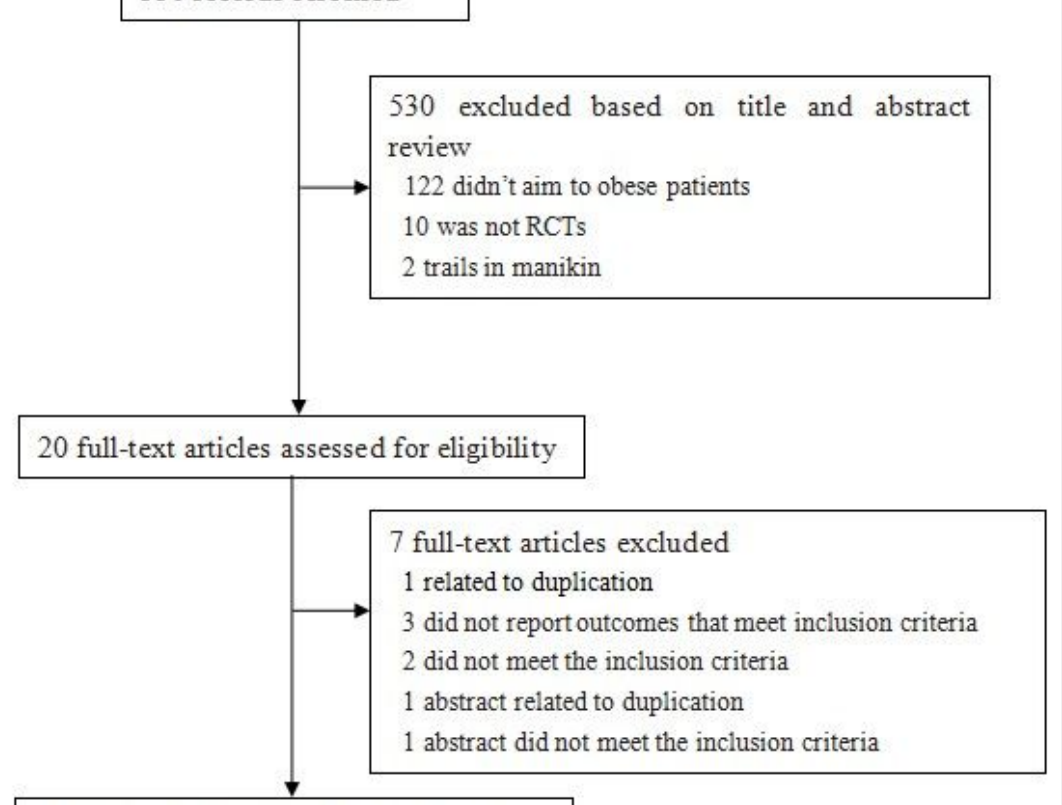

13 studies included in the meta-analysis

\section{Figure 1}

Flow diagram showing search and selection of studies. RCT, randomized controlled trial. 

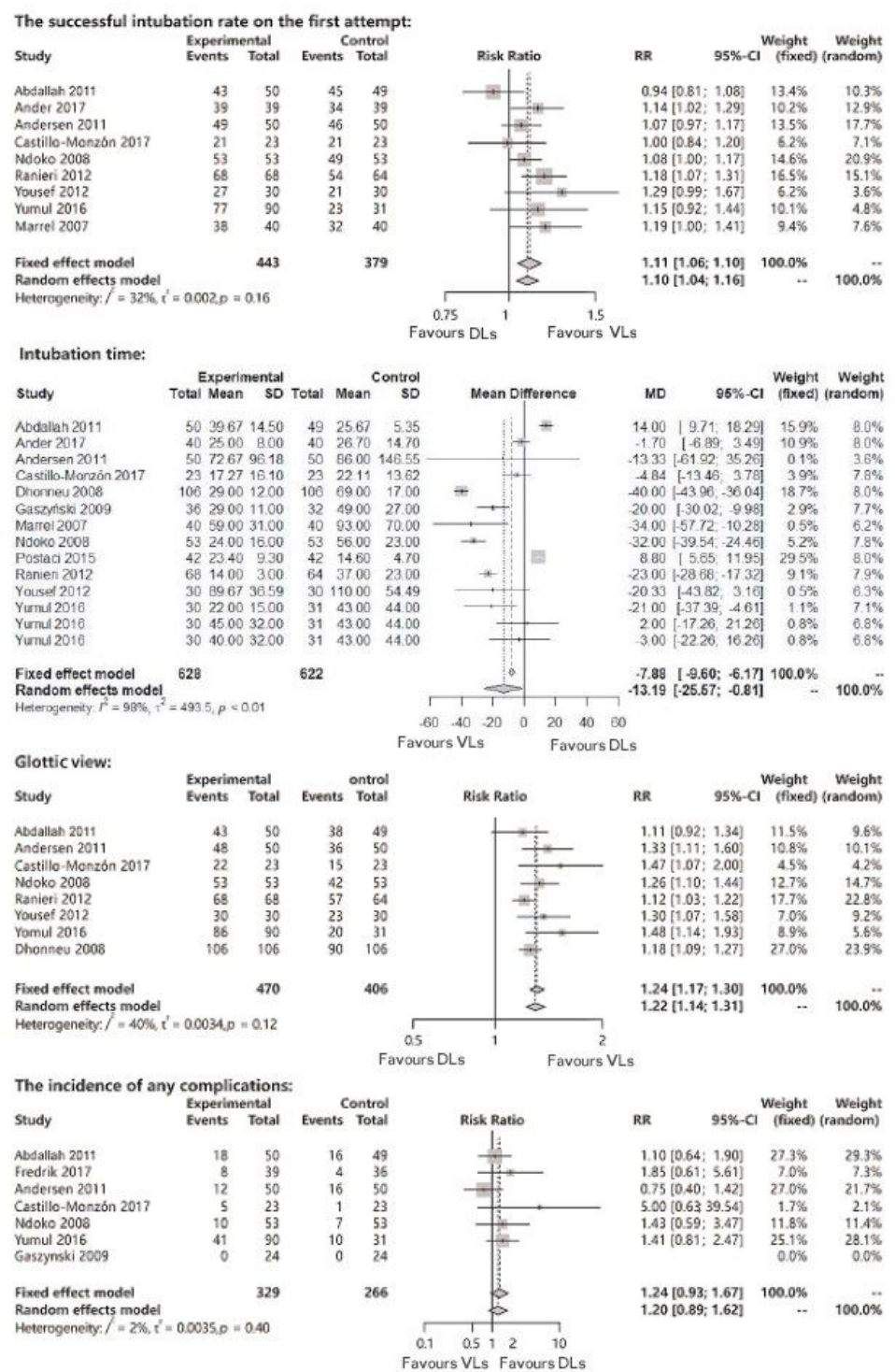

\section{Figure 2}

Forest plot of the risk ratio for the successful intubation on the first attempt, glottic view, the intubation time and the incidence of any complications in the pairwise meta-analysis between direct laryngoscopes and video laryngoscopes. The center of each square represents the relative risk for individua trials. The diamonds represent the pooled results. The corresponding horizontal line represents the $95 \% \mathrm{Cl}$. 
Comparison of Macintosh blade VLs versus conventional Macintosh DLs

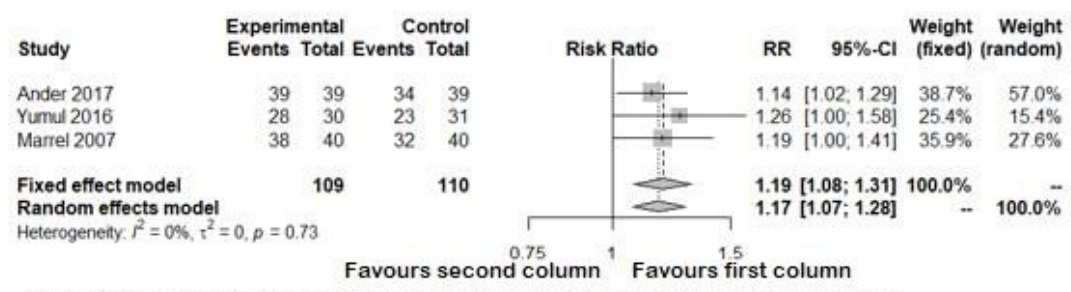

Comparison of angulated blade VLs versus conventional Macintosh DLs

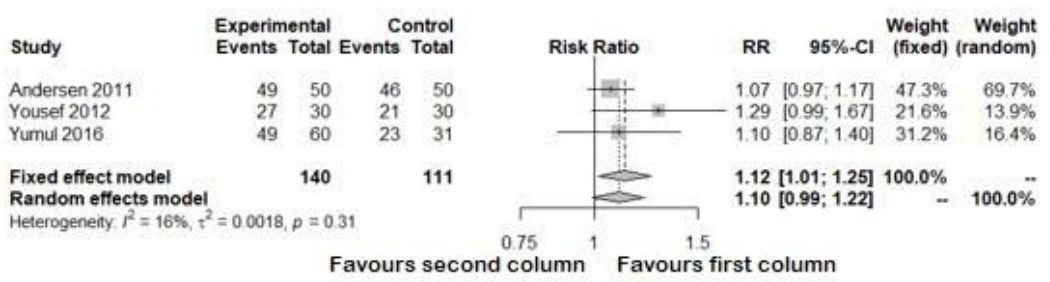

Comparison of side-channel blade VLs versus conventional Macintosh DLs

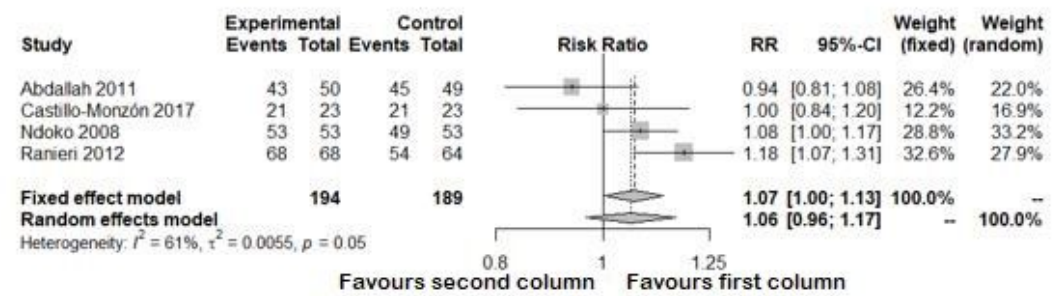

\section{Figure 3}

Forest plot of risk ratio for the successful intubation on the first attempt in the subgroup analysis. 
The successful intubation rate on the first attempt:

\section{Comparisons}

Macintosh blade VLs vs angulated blade VLs Macintosh blade VLs vs side-channel blade VLS Macintosh blade VLs vs conventional Macintosh DLs angulated blade VLs vs side-channel blade VLS angulated blade VLs vs conventional Macintosh DLs side-channel blade VLs vs conventional Macintosh DLs

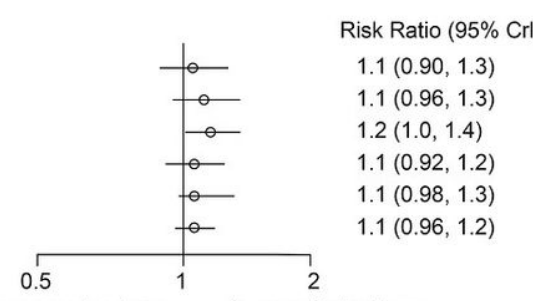

favours second column favours first column

Intubation time:

Comparisons

Macintosh blade VLs vs angulated blade VLs Macintosh blade VLs vs side-channel blade VLS Macintosh blade VLs vs conventional Macintosh DLs angulated blade VLs vs side-channel blade VLs angulated blade VLS vs conventional Macintosh DLs side-channel blade VLs vs conventional Macintosh DLs
Mean Difference ( $95 \% \mathrm{Crl}$ )

$6.2(-43 ., 53$.

$0.94(-41 ., 41$.

$-15 .(-52 ., 19$.

$-5.2(-38 ., 29$.

-22. $(-54 ., 11$.

-16. $(-37 ., 4$. $)$

favours first column favours second column

\section{Glottic view:}

Comparisons

Macintosh blade VLs vs angulated blade VLs Macintosh blade VLs vs side-channel blade VLs Macintosh blade VLs vs conventional Macintosh DLs angulated blade VLs vs side-channel blade VLs angulated blade VLs vs conventional Macintosh DLs side-channel blade VLs vs conventional Macintosh DLs

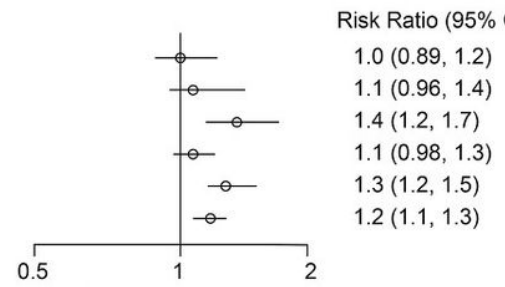

favours second column favours first column

The incidence of any complications:

Comparisons

Macintosh blade VLs vs angulated blade VLS Macintosh blade VLs vs side-channel blade VLS Macintosh blade VLs vs conventional Macintosh DLs angulated blade VLs vs side-channel blade VLS angulated blade VLs vs conventional Macintosh DLS side-channel blade VLs vs conventional Macintosh DLs

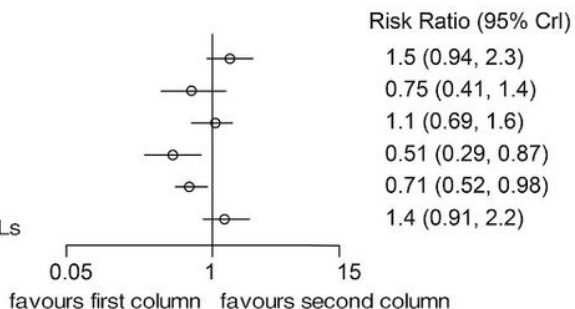

favours first column favours second column

\section{Figure 4}

Outcomes of the successful intubation on the first attempt, intubation time, glottic view, the incidence of any complications in the network meta-analysis.

\section{Supplementary Files}

This is a list of supplementary files associated with this preprint. Click to download.

- supplement1.docx

- supplement2.docx

- supplement3.docx

- supplement4.docx 